\title{
Strategi Pembuatan Buku Esai Fotografi tentang Kehidupan Masyarakat Bandungan
}

\author{
Daniel Kurniawan ${ }^{1}$, Margana ${ }^{2}$, Martien ${ }^{1}$ \\ 1Jurusan Desain Komunikasi Visual, Fakultas Seni dan Desain \\ Universitas Kristen, Surabaya \\ E-mail: daniel.kurniawan@peter.petra.ac.id \\ ${ }_{2}^{2}$ Program Studi Seni Rupa Fakultas Keguruan dan Ilmu Pendidikan \\ Universitas Negeri Sebelas Maret, Surakarta
}

\begin{abstract}
Abstrak
Bandungan merupakan sebuah kecamatan yang terdiri dari 10 desa. Keindahan alam serta kesejukan udaranya membuat Bandungan menjadi tujuan wisata di Jawa Tengah terutama wisatawan dari Semarang, Ungaran, Ambarawa dan Solo. Seiring berjalannya waktu, Bandungan mulai rusak oleh pembangunan yang terlalu cepat serta tidak bertanggung jawab. Perancangan buku ini merupakan media untuk memperkenalkan Bandungan secara lebih mendalam serta fungsinya dalam kehidupan khususnya bagi warga perkotaan sehingga diharapkan dari pengenalan ini, eksploitasi yang berlebihan terhadap Bandungan dapat berkurang dan keindahan alamnya tidak rusak dan tetap lestari. Dalam buku ini, kehidupan serta potensi dari tiap desa akan dibahas lewat bahasa verbal yang dikombinasi dengan ilustrasi fotografi sehingga informasi yang disampaikan akan lebih mudah dipahami dan menarik.
\end{abstract}

Kata kunci: Buku, fotografi, Bandungan.

\begin{abstract}
Bandungan is a countryside which has ten villages. The beauty of the scenery and the fresh air from Bandungan make it a tourist spot especially for tourists from Semarang, Ungaran, Ambarawa and Solo. Through time, Bandungan starts to suffer from irresponsible development. This book is designed as introduction to know Bandungan further about its function for society and citizens from the city around Bandungan. Hopefully through this book many people will recognize Bandungan not only as a spot for holidays and having fun but also realize its role in their lives, and that it will help reduce the exploitation of Bandungan and preserve its beauty. In this book, every potential from each village in Bandungan will be revealed through text which is combined with photography so the information will be easily understood and become more interesting.
\end{abstract}

Keywords: Book, photography, Bandungan.

\section{Pendahuluan}

Keindahan adalah salah satu hal yang senantiasa dicari dalam kehidupan manusia. Manusia mencari rumah yang indah untuk ditinggali, lingkungan yang indah untuk menetap, baju yang indah untuk dipakai. Bahkan keindahan alam pun dicari untuk dapat sejenak melepaskan diri dari kepenatan dan kejenuhan rutinitas. Berwisata ke tempat-tempat yang memiliki keindahan alam baik pantai maupun pegunungan. Indonesia sejak dahulu terkenal akan alamnya yang indah bahkan banyak diantaranya menjadi objek wisata terkenal seperti Gunung Bromo, Pantai Kuta, Pantai Senggigi, Danau Toba dan masih banyak lagi.

Di Jawa Tengah terdapat daerah yang sering menjadi tujuan wisata yaitu Bandungan. Bandungan adalah bagian dari wilayah Kabupaten Semarang. Sehingga keberadaannya tidak dapat dipisahkan dari kondisi Kabupaten Semarang. Kabupaten Semarang merupakan wilayah Daerah Tingkat (Dati) II dari kota Semarang. Wilayah Kabupaten Semarang merupakan rangkaian dari tiga kota yaitu kota Ungaran, Ambarawa dan Salatiga. Ketiga wilayah tersebut 
memang seolah berbeda, tapi merupakan kesatuan dari wilayah Kabupaten Semarang. Luas wilayah Kabupaten Semarang 95.020.674 Ha atau 2,92\% dari luas Propinsi Jawa Tengah. terdiri dari 24.822,50 Ha tanah sawah $(26,12 \%)$, tanah kering $70.198 .125,50 \mathrm{Ha}(73,88 \%)$. Secara geografis terletak pada $110014^{\prime} 54,75 "$ sampai dengan 110 0 39' 3" Bujur Timur dan 70 30' Lintang Selatan.

Secara umum, Kabupaten Semarang merupakan bagian dari kawasan perbukitan Dieng, sehingga wilayahnya umumnya memiliki suhu yang lebih rendah daripada kota Semarang. Ketinggian wilayah Kabupaten Semarang diantara 318 m $1.450 \mathrm{~m}$ diatas permukaan laut. Daerah dengan ketinggian terendah terletak di Kecamatan Ungaran $318 \mathrm{~m}$ dan tertinggi terletak di Kecamatan Getasan $1.450 \mathrm{~m}$, dengan suhu udara berkisar antara 23 - 26 derajat Celcius dan kelembaban udara berkisar 80 - $81 \%$. Tinggi tempat rata-rata $607 \mathrm{~m}$ dari permukaan laut, rata-rata curah hujan $1.979 \mathrm{~mm}$ dan banyaknya hari hujan adalah 104 . Kondisi ini terutama dipengaruhi oleh letak geografis Kab.Semarang yang dikelilingi oleh pegunungan dan sungai. Dapat dilihat bahwa secara geografis, kondisi alam di wilayah Kabupaten Semarang didominasi oleh pegunungan, sehingga wisata yang sangat dikedepankan adalah wisata peristirahatan yang menawarkan suhu yang sejuk dan pemandangan pegunungan sebagai daya tarik utama.

Menurut cerita yang ada di masyarakat, asal usul nama Bandungan berawal dari Pasutri K. Sanggem yang memperoleh wangsit untuk mencari sumur di lereng Gunung Ungaran, yaitu sumur yang airnya mengalir seperti sungai agar dia dapat memiliki anak. Setelah sumur ditemukan dan dia memiliki banyak anak, lalu dia mendapatkan wangsit lagi untuk menutup (membendung) sumur tersebut agar tidak menyebabkan malapetaka bagi kampung dibawahnya, dengan konsekuensi di desanya tidak akan ada sumber mata air dan akhirnya sumur tersebut ditutup dengan gong. Desa tersebut akhirnya di kenal dengan Bandungan (bendungan). Makam Kyai Sanggem berada di belakang Kantor Kecamatan Bandungan.

\section{Metode Penelitian}

\section{Metode Pengumpulan Data}

\section{a. Kuisioner}

Metode dengan cara membagikan kertas kuisioner yang berisi daftar pertanyaan seputar fakta, pendapat dan sikap, informasi dan persepsi yang diberikan audience. Metode ini digunakan dengan harapan memperoleh tujuan yang relevan dengan tujuan survey dan memperoleh informasi dengan realibilitas dan validitas setinggi mungkin (Singarimbun dan Effendi 131).

Teknik ini dilakukan untuk mendapat data dan mengetahui respon dari orang awam terhadap kondisi kota dataran tinggi Bandungan serta perubahan yang mereka rasakan.

\section{b. Observasi}

Observasi adalah kemampuan seseorang menggunakan pengamatannya melalui kerja panca indra mata serta dibantu panca indra yang lain. Metode observasi adalah metode pengumpulan data dimana data tersebut diperoleh dari hasil pengamatan peneliti (Bungin 142).

Dengan metode ini peneliti akan mendapat data data yang cukup akurat karena peneliti terjun langsung untuk melihat obyek yang diteliti.

\section{c. Wawancara}

Metode wawancara adalah proses memperoleh keterangan untuk tujuan penelitian dengan cara tanya jawab sambil bertatap muka antara pewawancara dengan responden atau orang yang diwawancarai, dengan menggunakan pedoman wawancara ataupun tanpa menggunakan pedoman wawancara. (Nazir 234).

Metode ini memiliki kelebihan yaitu data yang didapatkan lengkap dan akurat karena langsung dari narasumber primer. Dengan metode ini, peneliti dapat mengetahui hal - hal yang berkaitan dengan keindahan alam Bandungan serta tatanan masyarakat desanya langsung dari sumbernya seperti Dinas Pariwisata, tokoh-tokoh masyarakat Bandungan serta masyarakat desanya.

\section{Tinjauan Tentang Bandungan}

Sejarah keberadaan Bandungan tidak dapat dipisahkan dari sejarah keberadaan Kabupaten Semarang. Sejak 4 abad yang lalu dimasa PajangMataram, Kabupaten Semarang telah ada dengan ibukotanya Semarang. Pada jaman itu "Gemente" (Kotapraja) belum ada. Ki Pandan Arang II atau dikenal sebagai Raden Kaji Kasepuhan (15471553) merupakan Bupati Semarang yang pertama, dinobatkan tanggal 2 Mei 1547, berkuasa hingga tahun 1574 dan mendapat pengesahan Sultan Hadiwijaya. Pada masa itu berhasil membuat bangunan yang dipergunakan sebagai pusat kegiatan pemerintah kabupaten. Pada jaman 
Pemerintahan Bupati R.M. Soebiyono, "Gemente (Kotapraja)" Semarang lahir, yaitu tepat tahun 1906. Berdasarkan Stadblad tahun 1906 S.O 120 dibentuklah pemerintahan kota. Pemerintah Kabupaten Semarang yang dipimpin oleh seorang Bupati dan Pemerintah Kotapraja untuk wilayah Semarang yang dipimpin oleh seorang Burgen mester. Dan semenjak itulah terjadi pemisahan antara Kabupaten Semarang dengan Kotapraja Semarang hingga saat ini. Berdasarkan UU no 13/1950 tentang Pembentukan Kabupaten-kabupaten dalam lingkungan Propinsi Jawa Tengah, Kota Semarang ditetapkan sebagai ibukota Kabupaten Semarang. Namun Kota Semarang adalah kotamadya yang memiliki pemerintahan sendiri, ditinjau dari segi pemerintahan Kota Semarang sebagai ibukota Kabupaten sangatlah kurang menguntungkan, maka timbullah gagasan untuk memindahkan ibukota Kabupaten Semarang ke Kota Ungaran yang pada saat itu masih dalam status kawedanan. Sementara dilakukan pembenahan, tanggal 30 Juli 1979 oleh Bupati Kepala Daerah Tk. II Semarang diusulkan oleh Pemerintah Pusat melalui Gubernur, agar Kota Ungaran secara definitif ditetapkan sebagai ibukota Pemerintah Kabupaten Dati II Semarang. Dan ditetapkan dengan PP no 29/1983 tentang Penetapan Status Kota Ungaran sebagai Ibukota Pemerintah Kabupaten Dati II Semarang, yang berlaku peresmiannya tanggal 20 Desember 1983, yang terjadi pada masa pemerintahan Bupati Ir. Soesmono Martosiswojo (1979-1985).

Bandungan merupakan sebuah obyek wisata pegunungan yang terdapat di Kelurahan Bandungan, Kecamatan Ambarawa, Kabupaten Semarang yang berjarak $7 \mathrm{~km}$ dari kota Ambarawa dan berada $9 \mathrm{~km}$ dari kota Ungaran. Obyek wisata ini dapat ditempuh dengan kendaraan selama 1 jam di sebelah selatan Semarang atau sekitar 20 menit dari Ungaran, atau sekitar 15 menit dari Ambarawa melalui jalur pegunungan. Bandungan memiliki udara yang sejuk dan segar sehingga banyak sekali terdapat hotel dan motel. Adapun obyek wisatanya yang terkenal yaitu Candi Gedongsongo.

Bandungan mempunyai wisata yang cukup lengkap, meliputi wisata alam, wisata olahraga, taman bunga, areal perkemahan, pasar buah dan sayur dan tempat peristirahatan.

\section{Tinjauan Tentang Esai}

Esai adalah tulisan berupa prosa yang menguraikan suatu masalah secara sepintas dari sudut pandang penulisnya. Sebuah esai adalah komposisi prosa singkat yang mengekspresikan opini penulis tentang subyek tertentu. Sebuah esai dasar dibagi menjadi tiga bagian besar yaitu: pendahuluan yang umumnya berisi tentang latar belakang informasi yang mengidentifikasikan subjek bahasan serta pengantar mengenai subjek yang dibahas; tubuh esai yang menyajikan seluruh informasi tentang subjek yang dibahas umumnya ada permasalahan yang menyertai pembahasan tersebut; dan terakhir adalah konklusi yang memberikan kesimbulan hasil pembahasan mengenai subjek dimana dalam bagian ini disebutkan kembali ide pokok, ringkasan dari tubuh esai atau menambahkan observasi.

Menurut De Bono, ada dua model penalaran sehingga dapat mempermudah orang dalam melakukan pembagian terhadap esai. Pertama, model penalaran vertical (memusatkan perhatian dan mengesampingkan sesuatu yang tidak relevan) dan kedua adalah model penalaran lateral (membukakan perhatian dan menerima semua kemungkinan dan pengaruh).

Dari pembagian model penalaran ini, esai cenderung lebih kepada penalaran lateral karena esai cenderung acak dan tidak analitis serta dapat bersifat provokatif. Sebab esai menurut makna asal katanya adalah sebuah upaya yang tidak harus menjawab suatu persoalan secara final tetapi lebih ingin merangsang.

\section{Tinjuan Tentang Fotografi}

Kata Fotografi berasal dari kata "foto" yang artinya cahaya dan "grafi" yang berarti melukis. Jadi dalam fotografi, kehadiran cahaya adalah mutlak. Kita dapat membuat foto apabila terdapat cahaya di sekitar tempat dimana kita membuat foto. Fotografi dikenal kurang lebih 150 tahun yang lalu. Tapi bila kita membicarakan teori gambar yang dihasilkan lewat peran cahaya, maka ada catatan panjang dalam sejarah dunia fotografi bahkan sebelum Masehi. Alma Davenport dalam bukunya The History of Photography pada tahun 1991, menyebutkan bahwa pada abad ke-5 SM seorang pria bernama Mo Ti sudah mengamati gejala yang menjadi awal dari fotografi. Apabila pada dinding ruangan yang gelap terdapat lubang, maka di bagian dalam ruang itu akan terefleksikan pemandangan di luar ruang secara terbalik lewat lubang tadi. Kemudian pada abad ke-10 M, seorang ilmuwan Arab, Ibnu Al-Haitam menemukan fenomena yang sama pada tenda miliknya yang kebetulan berlubang. Kemudian ia menuliskan sebuah prinsip yang nantinya menjadi dasar kerja kamera. 
"Citra dari matahari pada saat gerhana, kecuali gerhana total, ketika cahayanya menembus melewati sebuah lubang kecil bundar, citra dari rembulan dapat dibentuk dari cahaya yang ditangkap oleh suatu bidang di hadapannya. Citra matahari dan bulan tersebut hanya nampak jika lubang yang dilewatinya cukup kecil. Jika lubang diperbesar, maka citra akan hilang."

Demikianlah, fotografi kemudian tercatat resmi pada abad ke-19 dan terpacu saat itu dengan kemajuan teknologi yang sedang gencar-gencarnya. Tahun 1839 dicanangkan sebagai tahun resmi fotografi. Pada tahun itu, di Perancis dinyatakan secara resmi bahwa fotografi adalah sebuah terobosan dalam dunia teknologi. Saat itu, rekaman dua dimensi seperti yang dilihat pada mata sudah bisa dibuat secara permanen. Penemu fotografi dengan pelat logam, Louis Jacques Mande Daguerre sebenarnya ingin mematenkan temuannya, tetapi pemerintah Perancis dengan pemikiran politiknya, mencetuskan ide agar temuan itu dibagikan secara cuma-cuma.

Dihadapkan pada masalah rumit dan kompleksnya proses fotografi, George Eastman (1890) terobsesi untuk membuat sistem yang sesederhana mungkin agar bisa dilakukan oleh semua orang. Akhirnya, ia menciptakan media film negatif yang diberi nama KODAK. (Triadi 2).

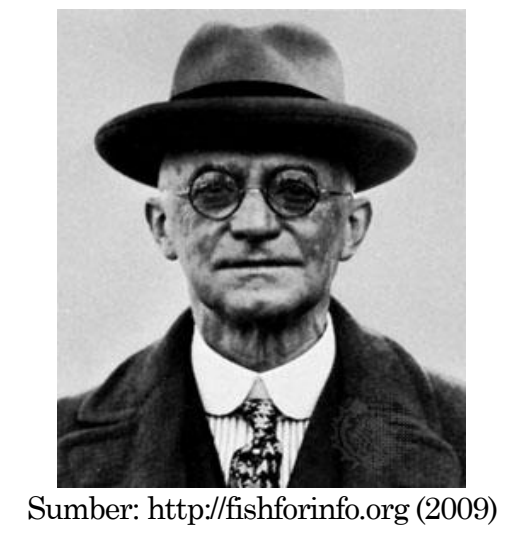

Gambar 1. George Eastman

Fotografi masuk ke Indonesia dan mulai berkembang sejak tahun 1930. Pada masa Perang Dunia II, dunia fotografi di Indonesia sempat berhenti berkembang tapi kemudian pada sekitar tahun 1960 kembali menunjukkan kondisi positif. Pada akhir dasawarsa ini, dunia fotografi makin berkembang dengan pesat. Didukung majunya teknologi yang kini juga merambah ke dunia fotografi. Akibatnya, fungsi fotografi pun tidak hanya sekedar untuk dokumentasi saja tetapi meningkat ke media komunikasi, jurnalistik, seni foto, foto produk dan periklanan.

\section{Tinjauan Tentang Buku Esai Fotografi}

Dalam Ensiklopedia Indonesia, buku didefinisikan sebagai semua tulisan dan gambar yang ditulis dan dilukis di segala jenis lembaran, seperti papirus, lontar, perkamen dan kertas dengan segala macam bentuk, bisa berupa gulungan yang dilubangi atau diikat dalam bentuk jilid. ( $1: 538$ ). Buku esai berarti semua tulisan dan gambar dimana dirangkai menjadi sebuah buku yang mana baik tulisan dan gambar yang ada memiliki tujuan untuk menjelaskan suatu kejadian atau peristiwa. Buku esai fotorafi berarti kumpulan foto terhadap suatu kejadian atau peristiwa yang memiliki kesinambungan satu dengan yang lain dan dirangkai menjadi sebuah buku.

\section{Tinjauan Budaya Masyarakat Bandungan}

Kawasan Bandungan merupakan sebuah daerah yang terbentuk dari desa-desa yang ada di sekitar Bandungan sekaligus menjadi subjek dari perancangan buku ini. Desa-desa itu adalah : Desa Jetis, Mlilir, Candi, Kenteng, Duren, Kelurahan Bandungan (sebelumnya termasuk Kecamatan Ambarawa), Desa Banyukuning (sebelumnya masuk wilayah Kecamatan Jambu), Desa Jimbaran, Pakopen, dan Sidomukti (sebelumnya masuk Kecamatan Bawen). Dari kondisi ini maka budaya masyarakat desa sangat mendominasi Bandungan.

Dalam UU Nomor 32 Tahun 2004 disebutkan pengertian desa sebagai kesatuan masyarakat hukum yang memiliki batas wilayah, yang berwenang untuk mengatur dan mengurus kepentingan masyarakat setempat, berdasarkan asal-usul dan adat istiadat setempat yang diakui dan dihormati dalam system pemerintahan Negara Kesatuan Republik Indonesia.

Dari defenisi tersebut, sebetulnya desa merupakan bagian vital bagi keberadaan bangsa Indonesia. Vital karena desa merupakan satuan terkecil dari bangsa ini yang menunjukkan keragaman Indonesia. Selama ini terbukti keragaman tersebut telah menjadi kekuatan penyokong bagi tegak dan eksisnya bangsa. menurut Paul H. Landis : desa adalah sebuah wilayah dengan ciri ciri sebagai berikut:

a. Mempunyai pergaulan hidup yang saling kenal mengenal antara ribuan jiwa.

b. Ada pertalian perasaan yang sama tentang kesukaan terhadap kebiasaan.

c. Cara berusaha (ekonomi) adalah agraris yang paling umum yang sangat dipengaruhi alam seperti : iklim, keadaan alam ,kekayaan alam, sedangkan pekerjaan yang bukan agraris adalah bersifat sambilan. 


\section{Visualisasi Budaya dan Kehidupan}

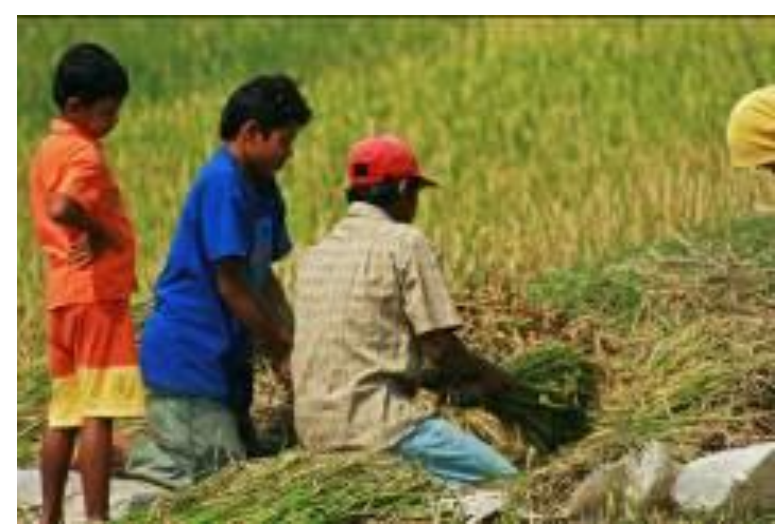

Sumber: Foto oleh Daniel (2009)

Gambar 2. Panen Padi

Sebagai masyarakat desa, pertanian adalah mata pencaharian yang pokok. Demikian juga bagi masyarakat Bandungan. Sebagian besar penduduknya adalah masyarakat yang agraris. Kita dapat melihat langsung kegiatan pertanian warga disana. Hasil pertanian dari Bandungan yaitu padi dan jagung.

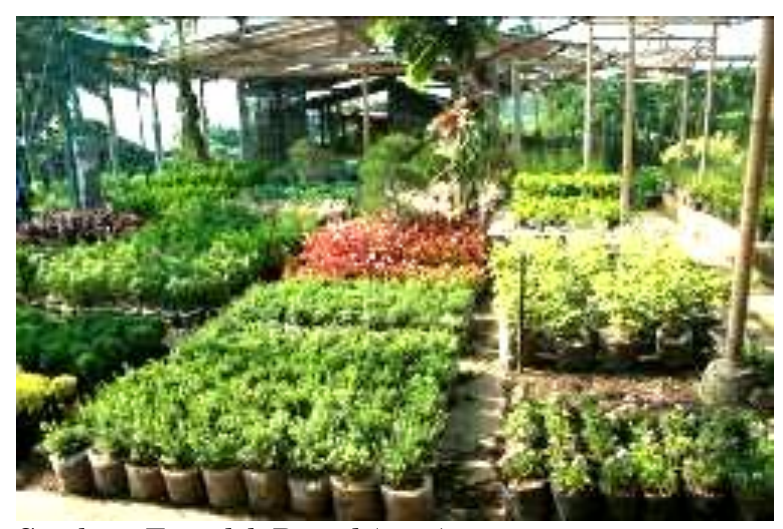

Sumber : Foto oleh Daniel (2009)

\section{Gambar 3. Pembibitan Bunga}

Pembibitan bunga adalah salah satu mata pencaharian bagi warga Bandungan, khususnya bagi warga desa Jambu. Pembibitan bunga ini memproduksi bunga potong seperti Anyelir, Catleya, Anggrek, dan sebagainya. Bunga potong dari Bandungan menyuplai kota Semarang, Demak dan sekitarnya.
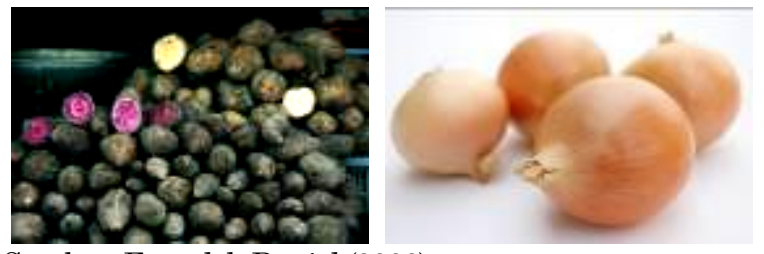

Sumber: Foto oleh Daniel (2009)

Gambar 4. Contoh Hasil Perkebunan
Sebagai daerah dataran tinggi, iklim dan suhu di Bandungan sangatlah cocok untuk perkebunan. Tidak sedikit penduduk yang hidup dari berkebun. Hasil perkebunan di Bandungan antara lain: ubi, bawang, sayuran (wortel, kentang,sawi, dll), buah (alpukat, kelengkeng, dll), kedelai dan sebagainya. Dari hasil-hasil agraris inilah kehidupan masyarakat Bandungan dapat berjalan. Bersinergi dengan alam, menjalani kehidupan. Kondisi alam ini menjadi area yang indah dan menyenangkan bagi para penjelajah untuk dapat berinteraksi juga dengan warga setempat.

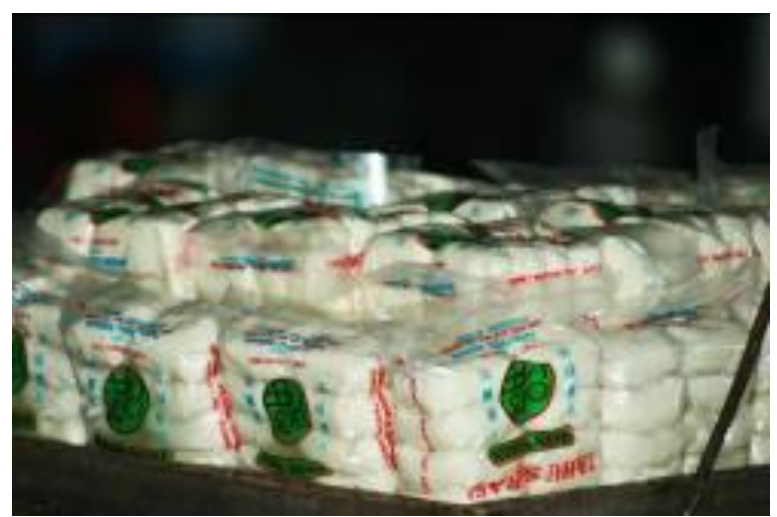

Sumber : Foto oleh Daniel (2009)

\section{Gambar 5. Tahu Bandungan}

Selain hasil bumi, Bandungan juga terkenal karena tahu dan susu kedelainya. Tahu Bandungan terkenal karena teksturnya yang berbeda dengan tahu pada umumnya. Padat tetapi kenyal. Selain itu ampas hasil pengolahan tahu juga diolah menjadi susu kedelai khas Bandungan yang biasanya menjadi buruan para wisatawan untuk dijadikan oleh-oleh.

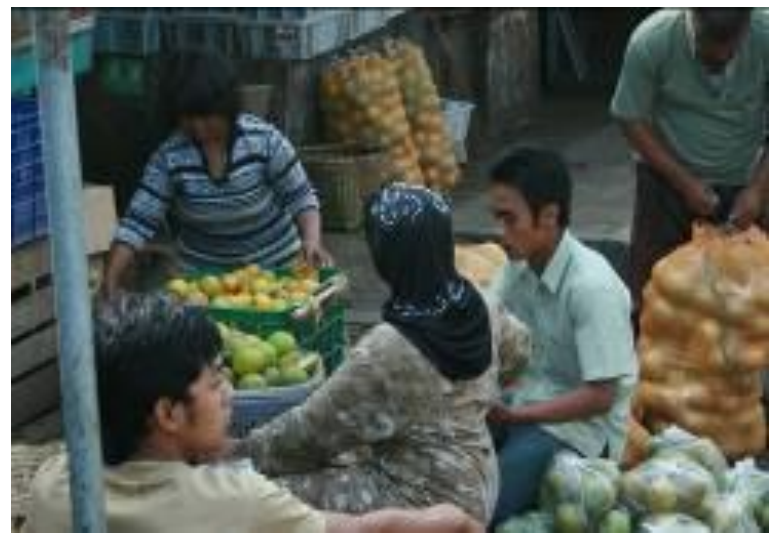

Sumber: Foto oleh Daniel (2009)

Gambar 6. Suasana Pasar

Selain tempat bertemunya penawaran dan permintaan, dalam tata budaya masyarakat desa, pasar menjadi sarana komunikasi antar warga desa itu sendiri. Menjadi tempat interaksi 
pengetahuan antar warga. Pasar Bandungan memiliki peran vital sebagai tempat pergerakan ekonomi disana sekaligus pusat interaksi budaya.

\section{Visualisasi Peninggalan Sejarah di Bandung- an}

Candi Gedongsongo menjadi saksi bisu bahwa Bandungan juga menyimpan sejarah perjalanan bangsa ini.

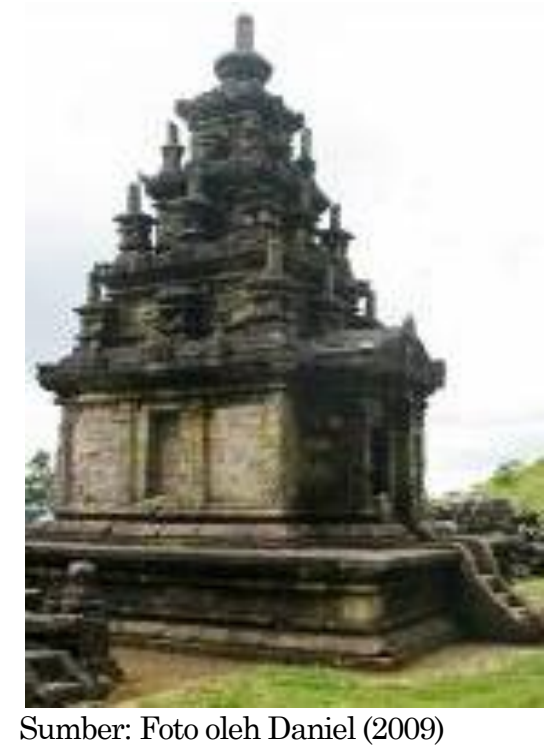

Gambar 7. Candi Gedongsongo

Candi Gedongsongo berada di desa Candi. Bangunan mirip Candi Dieng ini dijadikan sebagai tempat pemujaan dan abu jenazah. Situs purbakala ini ditemukan pertama kali dan kemudian digali oleh Thomas Stanford Raffles, gubernur Inggris yang memang sempat menduduki Indonesia pada tahun 1804. Diperkirakan bahwa candi ini dibangun pada masa pemerintahan Dinasti Syailendra sekitar abad 8. Candi Gedongsongo menjadi salah satu objek wisata yang cukup banyak menarik minat wisatawan yang berkunjung ke Bandungan. Sesuai namanya, "Gedong" dan "Songo". Kompleks candi ini terdiri atas sembilan candi, berderet dari bawah ke atas yang dihubungkan dengan jalan setapak bersemen. Mirip lereng-lereng bukit yang letaknya terpisah satu sama lain. Kompleks ini berada di ketinggian 1.200 meter diatas permukaan laut. Meski menyandang nama Gedongsongo, jumlah candi yang dapat dilihat hanya lima. Empat candi lainnya sudah rusak termakan waktu dan alam.

\section{Buku Esai Fotografi Bandungan}

Penggunaan media buku esai fotografi terhadap suatu peristiwa atau tempat memiliki kekuatan tersendiri. Setiap foto dapat menjelaskan lebih baik daripada seribu kata apalagi ketika berbicara mengenai alam, pemandangan dan peninggalan sejarah. Kekuatan visual dari foto yang dipadukan dengan esai dimana disertai dengan pengolahan kata yang baik akan memberi makna yang kuat. Sehingga dapat tercipta komunikasi antara penulis dengan pembaca. Apa yang hendak disampaikan penulis lewat karya esai fotonya dapat benar-benar tersampaikan kepada audience.

Visualisasi terhadap Bandungan ini bukan hanya lewat foto pemandangan, tetapi Bandungan adalah sebuah komunitas majemuk. Ada kehidupan dari orang-orangnya, kebudayaan hingga hubungan dengan alam. Sehingga interaksi manusia disana merupakan titik kunci terhadap apa yang hendak disampaikan. Petikan potret kehidupan masyarakat di Bandungan menunjukkan bahwa ada keindahan yang selama ini terabaikan dan tidak mendapat perhatian. Bahwa kemajuan zaman telah membuat mereka tertutupi oleh tingginya gedung-gedung pencakar langit, mobil-mobil mewah sehingga keindahan dari kehidupan tradisional menjadi terkikis.

\section{Visualisasi Layout}

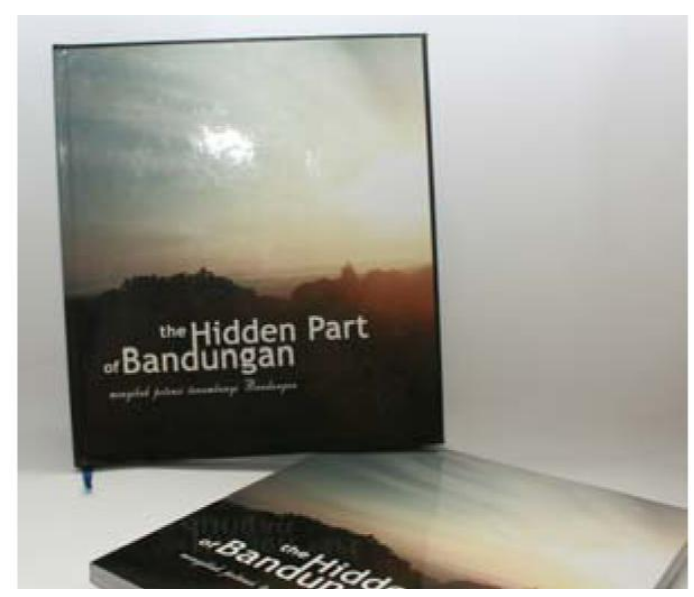

Sumber: Foto oleh Daniel (2009)

Gambar 8. Cover Buku

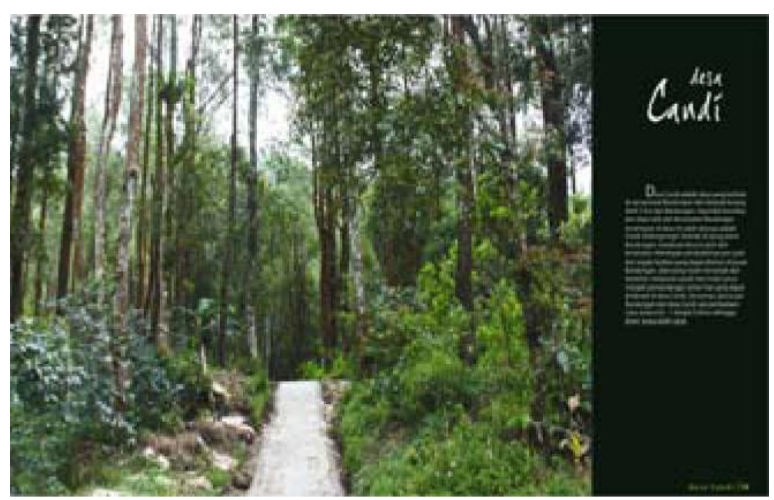



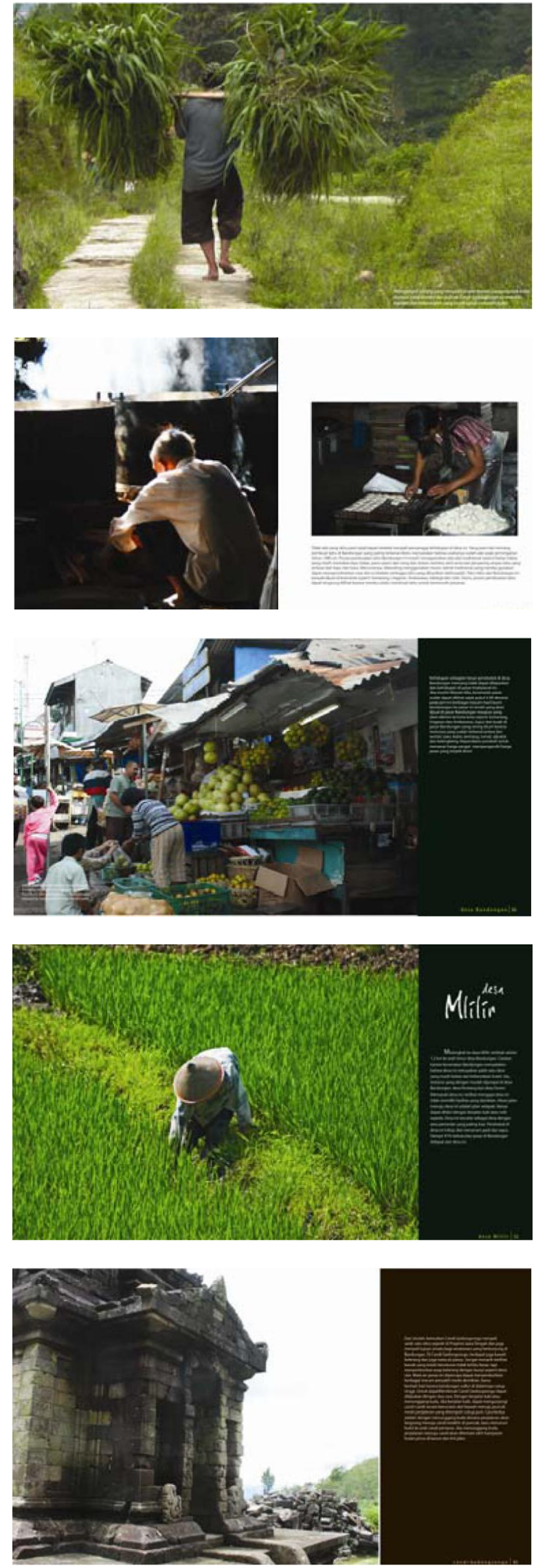

Sumber: Desain oleh Daniel (2009)

Gambar 9. Beberapa Layout

\section{Kesimpulan}

Kekuatan dari media yang bernama foto harus diakui mampu berbicara lebih kuat daripada buku. Satu lembar foto dapat memiliki pesan lebih dari seribu kata. Membuat buku esai fotografi sangat menarik dan menatang. Menariknya adalah bagaimana bereksplorasi dalam kata dan hasil foto.

Tantangan tersendiri dalam membuat buku esai fotografi adalah bagaimana menyusun cerita dari rangkaian foto serta bagaimana menyusun esai dari foto-foto tersebut agar tidak membosankan dan tidak membuat teks yang ada berkesan seperti sekedar judul dari foto yang ada. Ada baiknya bila sebuah buku esai fotografi dapat menceritakan hal-hal yang tidak biasa ditemui orang setiap hari atau hal-hal yang mungkin tidak menjadi pusat perhatian masyarakat. Melalui buku esai fotografi Bandungan ini, masyarakat diajak untuk dapat melihat sebuah kehidupan di daerah yang mungkin akrab bagi sebagian besar mereka tetapi tidak menjadi perhatian atau bahkan tidak dipedulikan.

Sebuah pengenalan hanya timbul dari sebuah kebiasaan mengunjungi Bandungan tanpa mengerti benar apa Bandungan itu, peran apa yang masyarakat Bandungan sudah berikan. Melalui buku esai fotografi ini, kiranya dapat menambah pengetahuan masyarakat akan keberadaan Bandungan yang bukan hanya sebagai tempat beristirahat di saat liburan atau tempat yang tepat untuk membangun vila dan resort. Bukan menolak sebuah kemajuan tetapi dengan melestarikan sesuatu yang alami akan memberi manfaat juga bagi kemajuan yang sudah ada.

\section{Daftar Pustaka}

Adams, Ansel. (1970). Camera and Lens. London: Morgan \& Morgan.

Ambrose, Gauvin and Paul Harris. (2003). The Fundamental of Creative Design. Singapore: AVA Book Production PTE. Ltd. "Book". Webster's New World College

Dictionary. $4^{\text {th }}$ ed. Ed. Michael Agnes. 1999. USA: Macmillan.

Bungin, Burhan.(2001) Metode Penelitian Sosial. Surabaya : Airlangga University Press.

Cullen, Kristin. (2005). Layout Workbook. Massachusetts: Rockport Publisher. Inc.

Davenport, Alma. (1991). The History of Photography. University of Mexico. Eastman, George. Diunduh 16 April 2009 dari http://fishforinfo. org 
Freeman, Michael. (1993). Complete Guide to Photography. Glasgow: Harper Collins Publisher.

Goodman, Allison. (2001). The Seven Essentials of Graphic Design. Ohio: How Design Books, 2001.

Hicks, Roger. (1991). The Art of Colour Photography. London: Tiger Books International.

Indonesia, Departemen Pendidikan dan Kebudayaan. (1989). Kamus Besar Bahasa Indonesia. (cet.3) Jakarta: Balai Pustaka, 1989.

Jennings, Simon. (1987). The New Guide to Illustration and Design. London: Quarto Publishing.

Kusrianto, Adi. (2007). Pengantar Desain Komunikasi Visual. Yogyakarta: Penerbit ANDI.
Mulyana, Deddy. (2002). Metodologi Penelitian Kualitatif. Bandung: PT Remaja Rosdakarya.

Nazir, Moh. (1998). Metode Penelitian. Jakarta: Ghalia Indonesia.

Nugroho, R. Amien. (2006). Kamus Fotografi. Yogyakarta: Penerbit ANDI.

"Objek Wisata Bandungan." Kabupaten Semarang Official Website. Diunduh 27 Desember 2008 dari http://www.semarangkab.go.id/objek wisata/Bandungan

Siebert, Lori and Lisa Ballard. (1992). Graphic Design Basic: Making a Good Layout. Cincinati: North Light Book.Soeprapto, F.X. Arie. Dasar-dasar Fotografi. Federasi Perkumpulan Seni Foto Indonesia.

Singarimbun, Masri dan Effendi, Sofian. (1986). Metode Penelitian Survei. Jakarta: LP2ES. 